\title{
Towards improved testing of modern asphalt pavements
}

\author{
M. N. Partl
}

Received: 22 October 2018/Accepted: 21 November 2018/Published online: 3 December 2018

(C) The Author(s) 2018, corrected publication 2019

\begin{abstract}
During the last 50 years, Rilem was continuously active in pre-standardization efforts aiming at gradually improving scientific and technological testing and analysis methods for refined understanding and characterization of bituminous binders and asphalt, both under well-defined laboratory and performance driven in-field conditions. This paper intends to highlight and provide a short overview on the international activities of Rilem's to date 18 technical committees (TC) on asphalt and bituminous binders. After some general background information, underlining the specific complexity of asphalt pavement materials in terms of rheological behavior and basic structural functioning, it is shown that these activities resulted in numerous recommendations, state of the art reports and conference proceedings, all produced on a voluntary basis by scientific and technical commitment of individual experts. This wealth of results was created by the TCs following an own systematic methodology for many years which, at the end of the day, allowed building up activities through the new TCs of today in a much more specialized but at the same time also more diverse
\end{abstract}

M. N. Partl ( $\square)$

Empa, Swiss Federal Laboratories for Materials Science and Technology, 8600 Duebendorf, Switzerland e-mail: manfred.partl@empa.ch

M. N. Partl

Division of Building Materials, KTH, Royal Institute of Technology, 10044 Stockholm, Sweden way. In view of this new flexibility and keeping in mind the previous success story of Rilem towards improved testing of asphalt pavements, future developments, challenges and interdisciplinary issues regarding bituminous road materials are outlined as potential starting point for future TC initiatives.

Keywords Rilem · Bitumen · Asphalt $\cdot$ Testing

\section{Introduction}

\subsection{The importance of asphalt}

The road infrastructure network made of asphalt pavements can be considered as the largest continuous building worldwide, stretching without interruption over the land mass of Europe, Asia and Africa linked by the asphalt layers that cover the Al Salam Suez Canal Bridge at El Qantara. It is reasonable to assume that the total length of continuous asphalt roads spans a distance of more than 3 times around the sun (according to IRF World Road Statistics 2017). In total, asphalt pavements cover probably an area in the order of magnitude of Cuba or Iceland. These facts make asphalt an important global building material.

Most of these asphalt roads are built in a traditional way with asphalt concrete, using locally available materials and based on experience driven, empirical try-and-error technology. Therefore, building asphalt 
roads has long been considered as a craftsmanship domain of experienced contractors and not as engineering or even scientifically appealing high-tech task. This is partly due to the fact that roads are not loadcarrying structures that may collapse in a dramatic safety relevant way, like bridges, but tend to deteriorate slowly, gradually losing their functionality, that can be compensated often through repair and maintenance actions or adoption of traffic regimes. It may also be one reason why asphalt pavement research and development has wrongfully suffered for decades from being in the shadow of another major building material, i.e. hydraulic cement concrete.

This paper is intended as a contribution to change this picture by providing a short retrospective of the last 50 years of asphalt research within Rilem (International Union of Laboratories and Experts in Construction Materials, Systems and Structure) as well as a short summarizing outlook on the opportunities that this important type of thermoplastic-viscoelastic materials may offer in solving pavement related challenges in the future, provided that the actual dynamic momentum in research can be maintained or even accelerated.

\subsection{Asphalt pavement material}

Asphalt is a scientifically exciting material of technical and social relevance which has recently attracted a boost of innovation for functional, environmental, sustainability and economic reasons. This development requires a sound understanding of the different components, i.e. the organic bituminous binder, inorganic stones (also known as mineral aggregates), air and various other potential ingredients such as fibers, non-hazardous waste materials, chemical additives, or RAP (Reclaimed Asphalt Pavement materials from old roads) - often referred as "black stone". It also requires the understanding of the interaction between the different components and their role in terms of mechanical performance, environmental compatibility and durability of the whole composite. This means not only addressing the phase of service and rehabilitation but also the phase of asphalt production, construction and demolition, followed by eventual recycling. In fact, easy recyclability is one of the main advantages of bituminous pavement materials, thus saving material resources in a sustainable and economical way. Research and development in that direction focuses on energy-saving and repeated recycling of RAP without loss of pavement performance and its increasing use in future pavements.

Bituminous binders are complex liquid byproducts of crude oil distillation with thousands of different hydrocarbonate molecules, eventually doped with polymers, like SBS (Styrene Butadiene Styrene). Other than with hydraulic concrete, the stone components of different sizes and surface properties are not round but generally crushed in order to produce an interlocked aggregate skeleton. Air in the pores of asphalt is another important component, serving for water drainage, traffic noise reduction or just as thermal expansion chambers for the viscous bituminous binder. In case of a continuous pore structure and crack network within the pavement or at the road surface, air supplies also oxygen which, together with elevated temperatures, has an aging effect on the bituminous binders. In most cases aging means embrittlement thus increasing the risk of cracking. However, aging can also mean the contrary, for example when overheating of polymer bitumen occurs, causing the long molecular chains of the added polymer getting "broken" and shortened.

Understanding the binding mechanisms between bitumen and the stones in asphalt is crucial for manipulating its functionality and performance as a whole under stochastic traffic loading as well as climatic stresses from temperature changes and action of water. Water, in particular, can create deboning or stripping of binder from the stones because of a higher affinity of water to stones than bitumen. Bonding is also affected by the chemical characteristics of the stones. Granite, for example, is more prone to bituminous binder stripping than limestone.

Depending on its inner structure and its load carrying function one can distinguish three different structural types of asphalt as shown in Fig. 1 (Partl et al. [31], Rilem state-of-the-art reports):

a. Mastic concept (no voids, stones "swim" in binder, binder gluing is dominant)

b. Packing concept (some voids, densest stone packing, friction between stones dominant)

c. Skeleton concept (high voids, gap graded stone skeleton, lateral confinement dominant).

Different technologies are available for asphalt production. The classical way is producing hot asphalt concrete at temperatures around $160{ }^{\circ} \mathrm{C}$, where mixing and compaction relies on the viscosity of the hot 


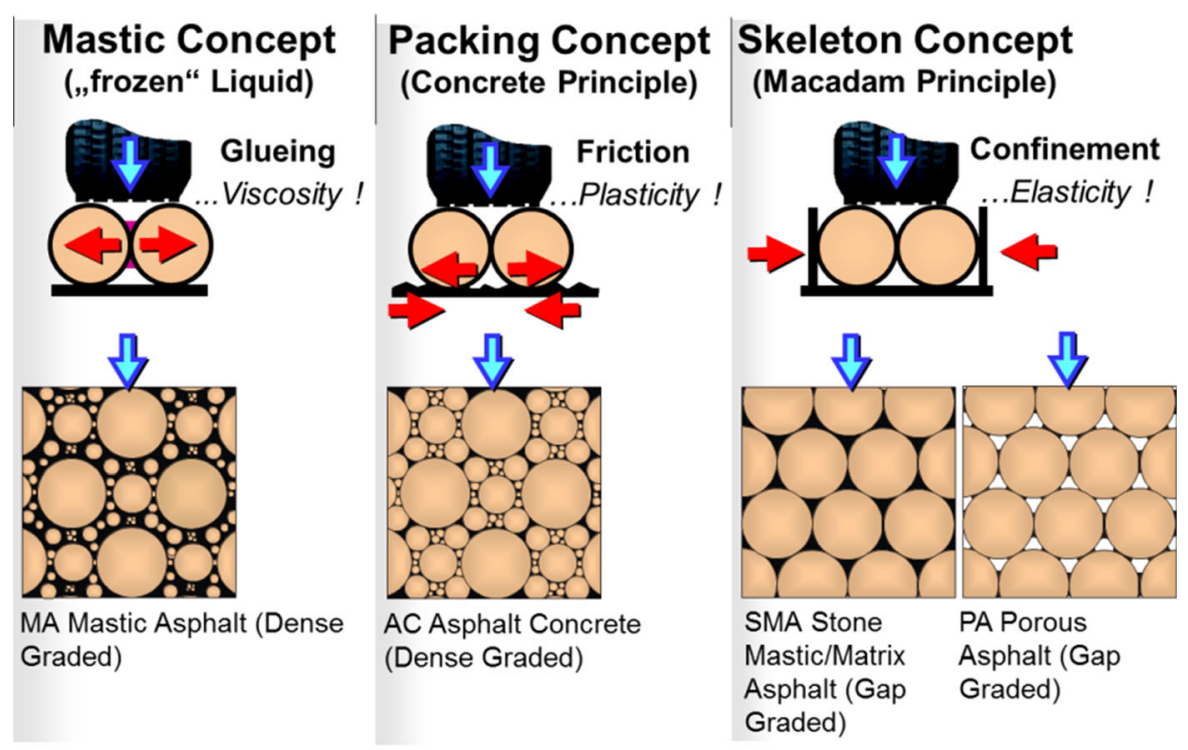

Fig. 1 Basic concepts for structural functioning of asphalt pavement mixtures

bitumen and the thermal capacity of the heated stones. In addition, for energy saving or other special environmental reasons, asphalt is sometimes produced with warm or even cold mix technology, relying on foam bitumen or bitumen emulsions. However, this is often done at cost of performance and life time since these materials still tend to be inferior to hot asphalt pavement mixtures.

Asphalt is a very complex thermoplastic-viscoelastic type of material. It is a highly time- and temperature-dependent recyclable composite which is a challenge to understand in its complexity from both an intrinsic material focused and a long-term functional performance point of view. Hence, almost countless proposals for modelling the mechanical behavior of asphalt and its binder have been proposed by combining simple rheological elements to basic "rheological molecules" as indicated in the rheological triangle in Fig. 2 (Part et al. [31], Rilem state-ofthe-art reports), eventually combining them to serial and parallel "rheological polymers", e.g. through Prony series approach. Others viscoelastic models are based or inspired by complex nonlinear element configurations, for example, the 2S2P1D model in Fig. 3a by Olard and Di Benedetto [5]. An example of a nonlinear viscoelastic model used as background for incorporating damage effects in case of arbitrary short and long-term stress-reversals is shown in Fig. $3 \mathrm{~b}$ $[6,7]$. However, also nonlinear viscoelastic models either with or without damage considerations are used that are not based on rheological element configurations, but directly rely on thermodynamic considerations [9] and the introduction of so-called pseudostresses, pseudo-strains and pseudo-stiffnesses, as required for the Viscoelastic Continuum Damage theory (VECD) by Lee and Kim [3].

During the last 50 years, Rilem has contributed considerably to the numerous attempts of understanding and characterizing asphalt and its binder, trying to provide a platform for international voluntary knowledge exchange and evaluation of different experimental and modelling approaches in interlaboratory comparison initiatives. Rilem has produced numerous recommendations [11-27], state-of-the-art reports [28-33] and conference/symposia proceedings [34-55].

\section{0 years asphalt and bituminous binder in Rilem}

\subsection{History}

Rilem activities in the asphalt materials sector started 21 years after the foundation of Rilem with a first symposium 1968 in Dresden (Germany). It was the cradle of a first technical committee TC 17-BM on bituminous materials followed by four others that were focusing on binder testing and in one case specifically on crack prevention in roads. These 
Fig. 2 Rheological triangle
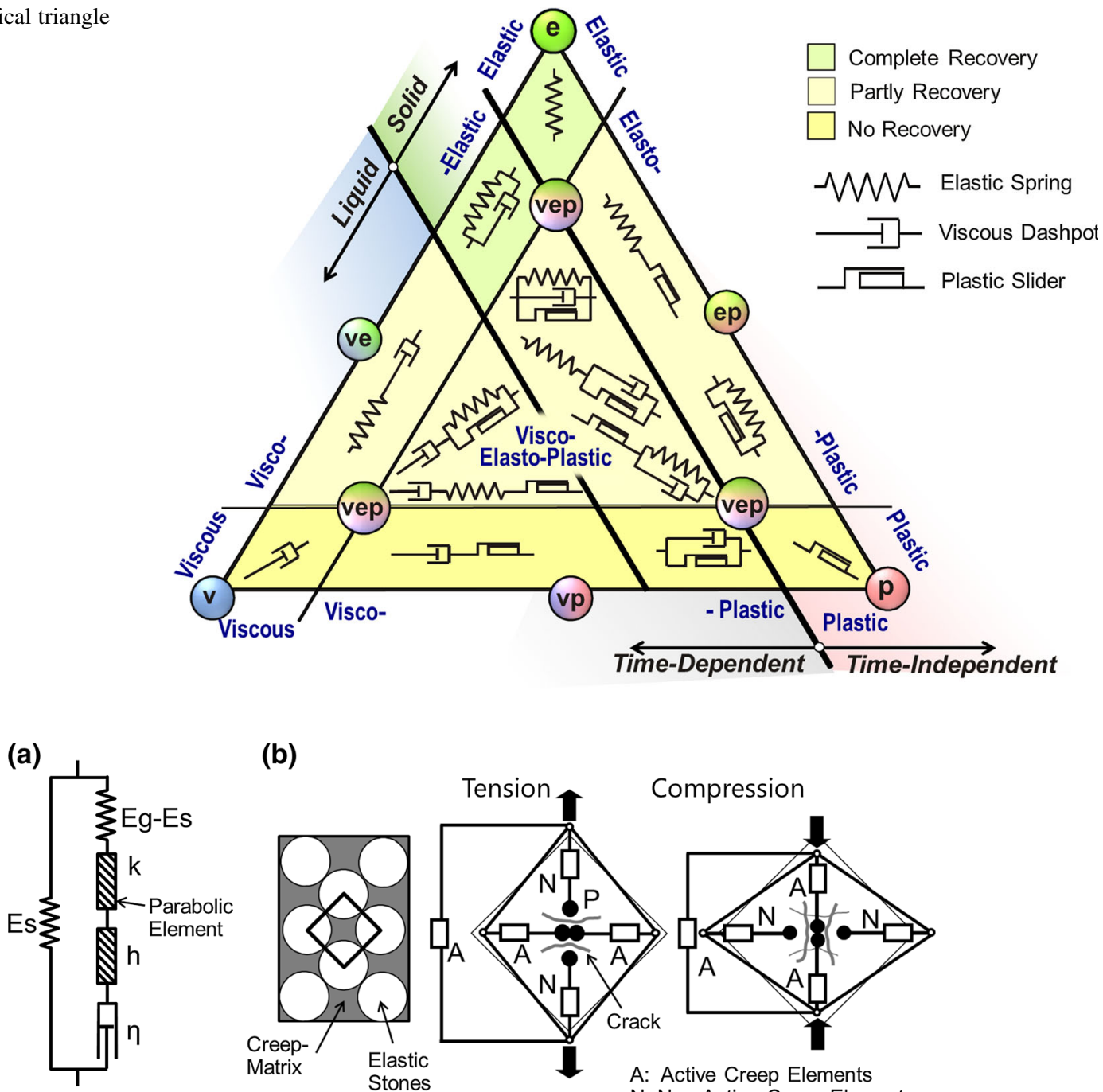

(b)
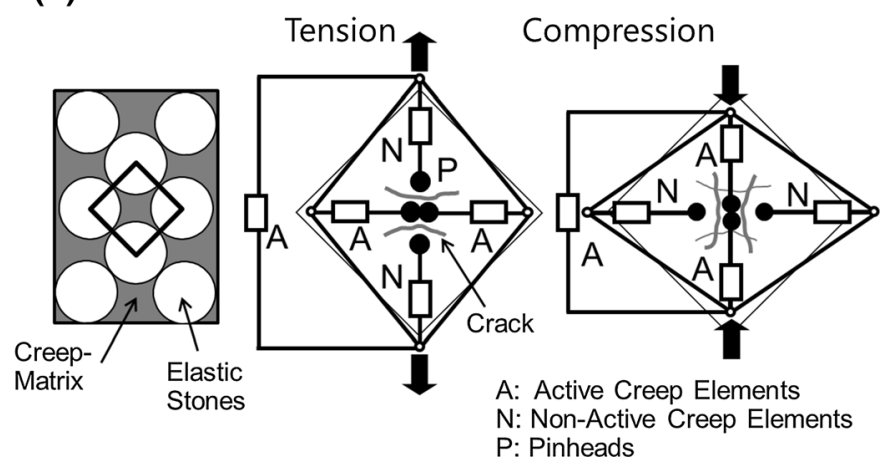

Fig. 3 a Nonlinear viscoelastic 2S2P1D model [5], b nonlinear viscoelastic [6]

pioneering technology oriented TCs organized various symposia and seminars in central Europe that resulted in different reports and basic recommendations of prestandardization character, e.g. on sampling of hydrocarbon binders, determination of density, needle penetration and binder recovery (see recommendations listed in the reference section). An overview on the different TCs during the last 50 years and the conferences and symposia is provided in Table 1 .

From 1999 until 2013 these TCs were followed by five performance and advanced testing oriented TCs, that were treating specific subjects no longer from a purely technological but also from a fundamental engineering point of view. Two of them were dealing with crack development in the field, crack propagation on laboratory specimens, modeling of crack initiation and propagation, interface debonding and advanced measurement system. Three TCs concentrated on binder and mixture testing, such as binder fatigue and pavement rutting, measurement of Poisson's ratio in mixtures and recyclability of mixtures, supported by studies of modeling approaches and performance prediction evaluations on field test sections in Austria and Portugal. In Italy, tests on field sections were conducted for studying the characterization of interlayer bond, also considering the effect of grid 

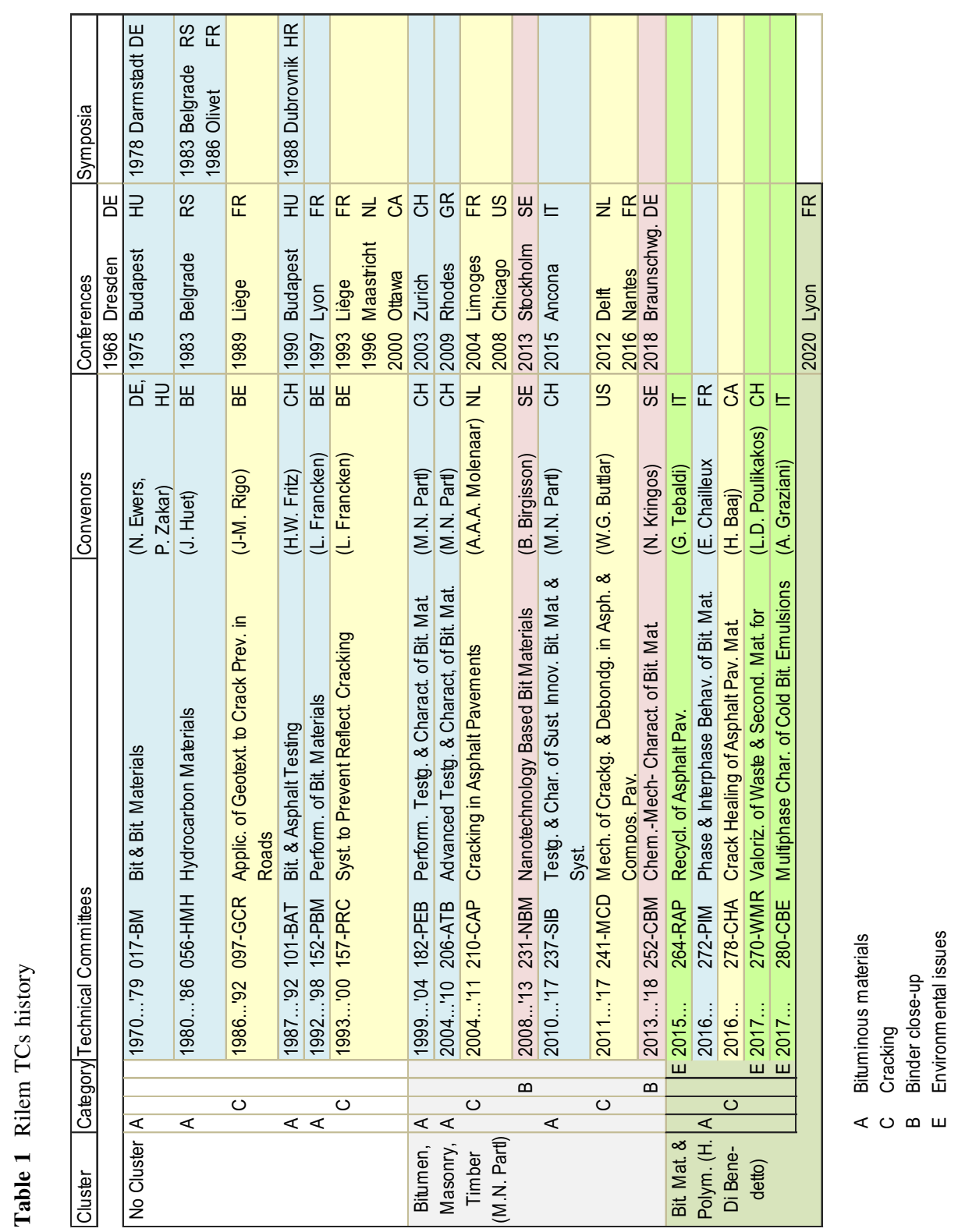
Fig. 4 Rilem methodology and testing domains where Rilem was active (marked with Rilem logo)

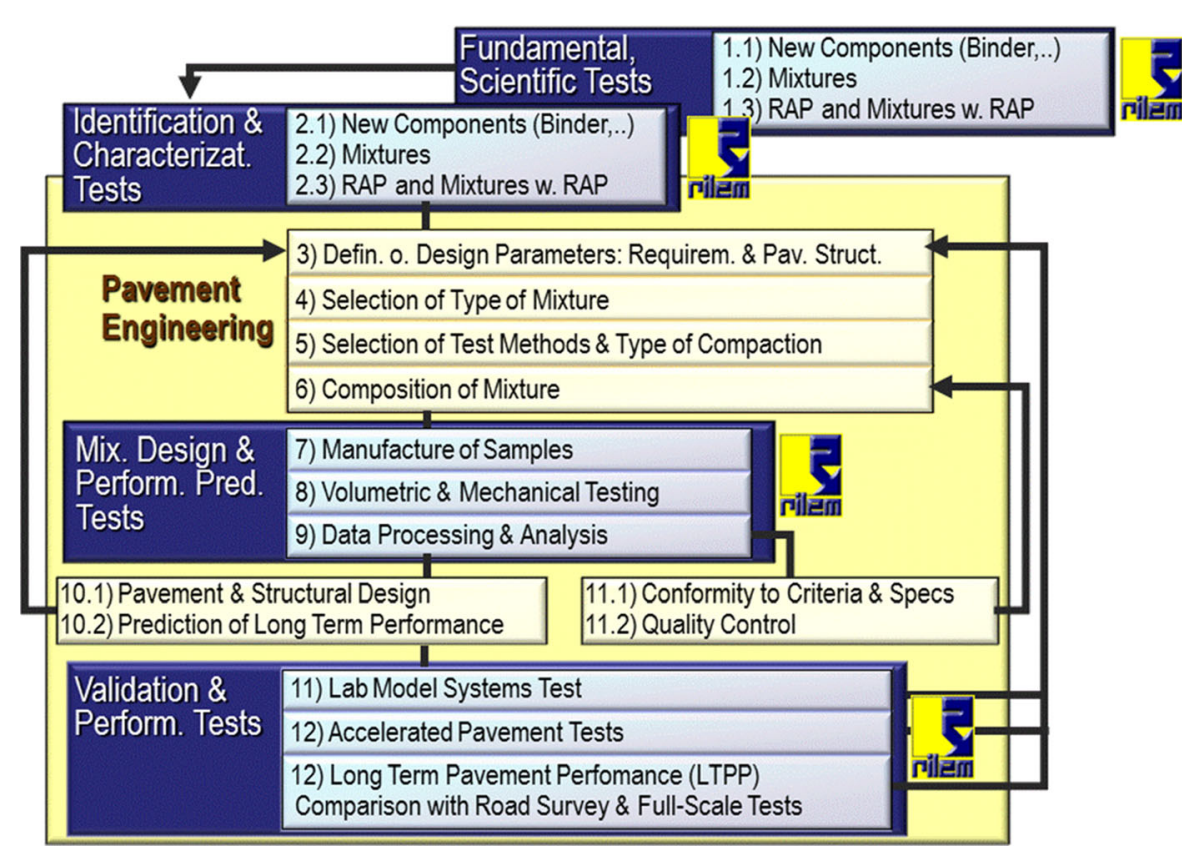

reinforcement. The different binder and mixture topics of the three TCs were investigated in comparative and interlaboratory tests by specific task groups (TG) according to the methodology shown in Fig. 4 (Francken [29], Rilem state-of-the-art reports). Later, within that time period, two other TCs were added, focusing on special binder close-up questions related to micro- and nano-scale issues, such as bitumenaggregate interaction, as well as chemo-mechanical characterization techniques of bituminous materials. These TCs concentrated on subjects that were also important for the other TC's but too detailed and complex for being investigated within their scope. Coordination of all these TC activities was conducted within the Rilem TC-Cluster responsible for bitumen, masonry and timber based materials.

Following this time period, new, to day active TCs were established, aiming at further improving the understanding of bituminous materials from an indepth material science and environmental point of view. These TCs deal with phase and interphase behavior of bituminous materials, asphalt pavement recycling (RAP) and multiphase characterization of cold bitumen emulsion materials. Moreover, two TCs were created that are working on evaluating new test and characterization methods regarding crack-healing of asphalt pavement materials as well as valorization of waste and secondary materials for roads. These TCs are now running under the coordination by Rilem TCCluster on bituminous materials and polymers.

\subsection{Some achievements}

Achievements of all these bituminous materials related, voluntary activities are numerous. Early Rilem recommendations had clear influence on standardization of early binder characterization tests. Later, it influenced also standardization on stiffness testing of binders and asphalt mixtures, providing a comparison between different mechanical configurations and data on repeatability and reproducibility from interlaboratory tests. Recommendations, state of the art reports and proceedings in the bituminous materials domain are listed in the Reference section below.

Summarizing all important results created by the voluntary work of Rilem TCs over the last 50 years would certainly go beyond the scope of this short paper. However, as illustration, a selection of findings and achievements, primarily elaborated in the bituminous materials TCs series " $\mathrm{A}$ " in Table 1 is mentioned below.

In early Rilem state-of-the-art reports the benefit of considering cyclic viscoelastic behavior not only through master curves but also through Black diagrams and Cole-Cole presentations was demonstrated 
[29]. Moreover, Rilem pavement performance prediction evaluation (PPPE) in Portugal and Austria clearly revealed that prediction of rut depth may vary considerably depending on the assumptions and models used [30]. It was found that fatigue predictions were in better agreement than for rutting. As for rut tests with wheel tracking devices, it was observed that the small wheel tracking test produced more severe and faster rutting than the wheel tracking test with large wheels (Di Benedetto et al. in Partl et al. [31]). It became clear that such performance oriented tests are only meaningful for comparing similar mixture types. Hence, tests that are reasonable for asphalt concrete (AC), may not be conclusive for other mixtures, such as mastic asphalt.

Another good example of Rilem activities is an aging protocol, developed for producing reclaimed asphalt from ordinary loose AC, mixed either in the lab or in an asphalt plant (De la Roche et al. in Partl et al. [31]). The protocol recommends $4 \mathrm{~h}$ short-term oven-aging of the $\mathrm{AC}$ mixture at $135^{\circ}$ for simulating transport and placing, followed by 9 days long-term oven-aging at $85{ }^{\circ} \mathrm{C}$ for simulating service life. It was found that the proposed short-term mixture aging was more severe than rolling thin film oven testing (RTFOT) on virgin bitumen alone and that the usual standardized combined aging of virgin binder in RTFOT and pressure aging vessel (PAV) was quite low as compared to the proposed combined short- and long-term aging on loose AC mixtures.

Recently an extensive in-depth Rilem interlaboratory study on measuring the complex Poisson's ratio of an AC on cylindrical specimens, horizontally taken from an AC slab, has been performed (Graziani et al. in Partl et al. [32]). This investigation was motivated by the fact that measuring complex Poisson's ratio requires extreme experimental care in terms of specimen preparation, temperature control, accuracy and experimental boundary conditions. It was found that the same shift factor holds for the complex Poisson's ratio as for the complex modulus and that, in this case, differences in Poisson's ratio were independent from the radial direction of measurement, i.e. in the horizontal and vertical direction of the AC slab. The study demonstrated that assuming a constant Poisson's ratio for viscoelastic modelling is a clear oversimplification.

Unfortunately Rilem were not always successful. In two successive TC's, an effort was made to deal with the subject of compaction, since this phase is a key step for durability of a pavement. At the beginning, there was always a lot of enthusiasm, but when it came to the interlaboratory task of comparing different test and characterization methods, practical obstacles prevailed. Nevertheless, compaction is such an important issue that one can only hope that Rilem will be able to provide a contribution when time comes. A somewhat similar situation occurred, when dealing with comparing characterization of aggregate structures. Rilem was able to report success with a specific 2D imaging software, only requiring images taken by a simple copy machine, but was not able to establish an interlaboratory test on computed tomography CT application, since, at that time, these devices were not as common as they are today. Again, this is still work to do. One can generally state that, in some cases, Rilem appeared almost too fast in trying to establish interlaboratory tests. Actually this may probably be the case when comparing dynamic interlayer shear test devices, since the number of those devices is probably still too limited.

\section{Outlook}

\subsection{Open testing challenges for Rilem}

The complexity and variety of bituminous materials together with their application will most probably further increase in future due to higher user related, economic and environmental expectations and requirements, e.g. in terms of sustainability, availability of material resources and energy efficiency. Rilem can and will certainly continue on a voluntary basis in contributing to the international community through further interlaboratory activities, experimental recommendations, state of the art reports and conferences, focusing on empirical, mechanistic and scientific aspects of bituminous materials in a multiscale way (Fig. 5). This growing complexity and variety may require an even more extended shift from prestandardization oriented characterization testing to comparative evaluation and assessing of different modelling approaches for in-depth fundamental understanding of the material's behavior and its influence factors. It goes without saying that this means also more efforts regarding performance and validation testing, being well aware of the fact that 


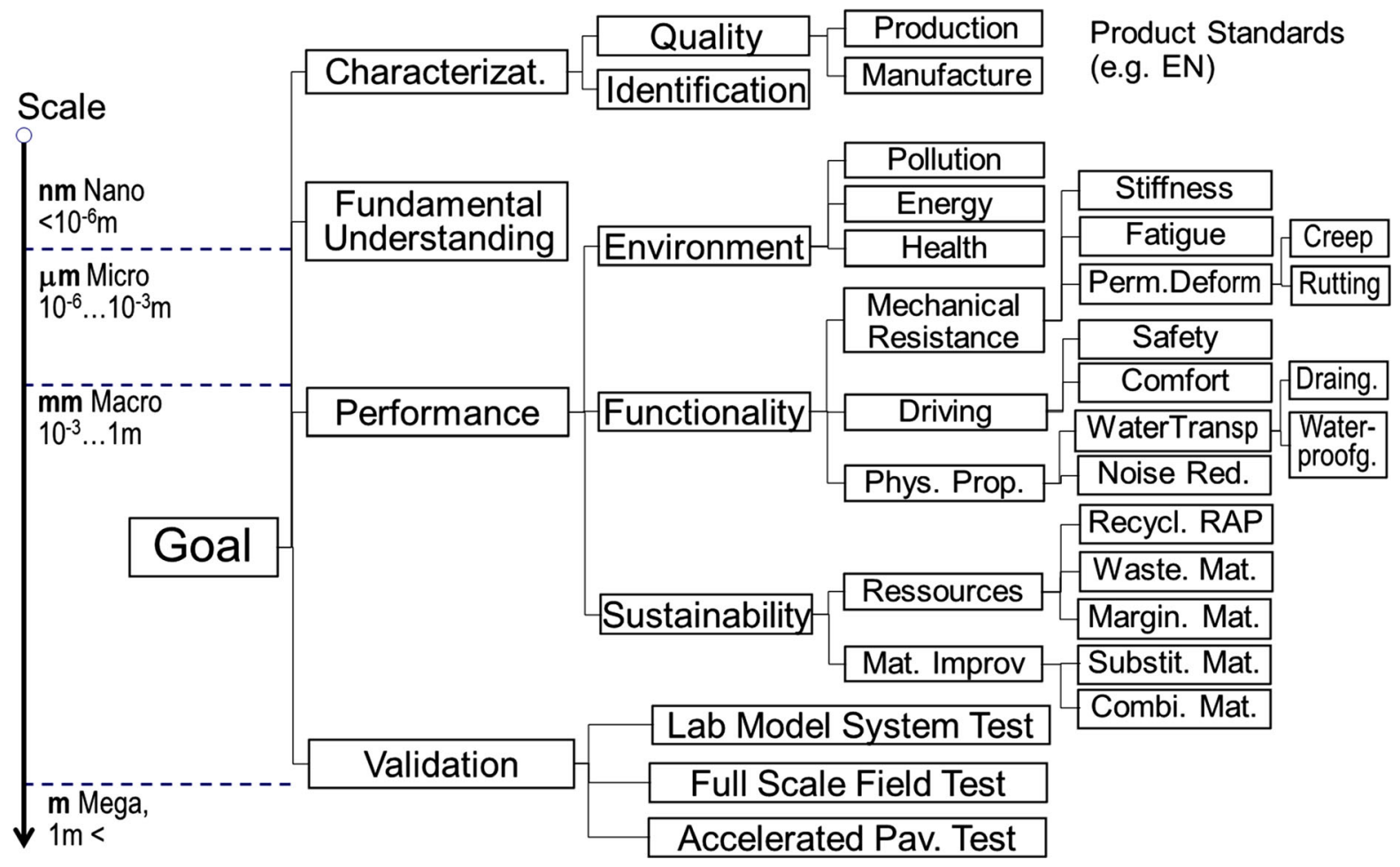

Fig. 5 Future multi-scale focus area of Rilem for testing in the field of bituminous materials

performance does not exclusively refer to mechanical but also to environmental performance, such as noise reduction. Some subjects, such as driving safety and comfort or full-scale accelerated pavement testing (APT) may be completely new for Rilem. Moreover, understanding and characterizing paving, compaction and effects during transport of asphalt pavement materials from plant to job site have been put on the to do list of Rilem TCs but have proven quite tricky for consideration, so far. Hence, these topics can be considered practically new for Rilem. Other subjects, like recycling and mechanical resistance are not so new, but will still require considerable refinements and adjustments of existing test methods and methodologies. This is particularly true for the use of alternative material components such as residual materials from industry, post-consumer, demolition and marginal materials as well as new material components with specific new properties. Besides of functionality questions, also health and environmental issues must be studied very carefully in order to avoid "linear landfills" and potentially jeopardizing future generations.
In any case, since the asphalt community is relatively small, it may well be possible that the continuation of producing and analyzing experimental results on a purely voluntary basis may soon come to its limit. Close alliances of Rilem with project funding organizations without betraying Rilem's mission and independence may be a way to overcome or mitigate this situation.

\subsection{Some future pavement developments relevant} for Rilem

In future, use, traffic regime and functions of roads will change significantly, at least in regions with high traffic volume, such as urban environment.

As for use, strong tendencies exist nowadays towards autonomous driverless cars. This will result in completely different traffic regimes, such as narrowly canalized heavy track platooning. On the one hand, this canalized traffic will increase traffic loads and frequency and may therefore boost the performance requirements for a road; on the other hand, the same automatization would allow canalizing the traffic periodically to a slightly shifted wheel track, 
leading to a more homogeneous and probably less severe loading of the road. New mobility and modular traffic models may also require a stricter separation of different traffic participants on roads (cars, trucks, bikes pedestrians) and probably lead to different user tailored individual pavement structures. Roads in the future will also be smart with a lot of built-in sensors that will interact with cars, also continuously informing about the state of the road surface (ice) or the intrinsic road pavement conditions (moduli, cracks, moisture, etc.). Sensors will deliver warning and advise for changing the traffic regime, when the roads "feel" mechanically overloaded. In this context, it is beneficial for the structural integrity of the pavement that, nowadays, these sensors become smaller and smaller (MEMS) as well as wireless thanks to multihop architecture (e.g. [10]). However, "smart" does not necessarily mean pavements with built-in sensors. It can also mean pavements that are self-adoptive or reactive to changing situations. This means, for instance, pavements with self-changing optical appearance for improving visibility during the night or in case of frost. It may also mean pavements with inbuilt phase change materials (PCM) in order to mitigate temperature peaks in the pavement [8]. Efforts are also ongoing on developing pavements that are "vaccinated" with particles as crack healing promotors, such as micro-capsules containing softening agents or electromagnetically sensitive particles that can be activated trough induction or alternating magnetic fields [2].

As far as construction methods are concerned, material tailoring and road paving will be more and more automatized with robots for quality reasons and construction under all-weather $24 \mathrm{~h}$ conditions as well as for allowing placement of refined complex anisotropic sandwich structures, built from specific

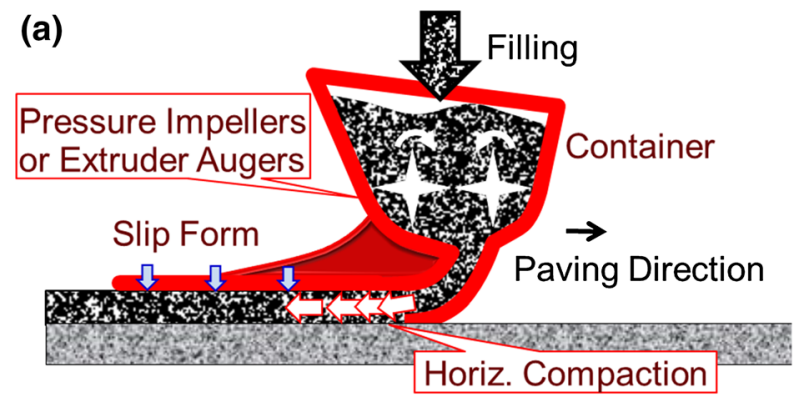

elements and components. This will no longer be achieved by designing roads in a classical way. However, durability, safety and recyclability principles must be respected also in these cases. New construction methods may also include refined industrialized prefabrication, such as laying strings of sandwich or hollow modular road plates or by placing carpet like systems. Attempts in that direction have already been performed some time ago [4]. Regarding in-place construction, even more futuristic alternatives than compaction with rollers and pneumatic compactors may be considered, such as 3D printing systems or pavement extruders for horizontal "compaction" by temporarily creating a confined pressure volume in a slip form through impellers or extruder augers (Fig. 6a).

Given the large land area that pavements are covering and the considerable investments they represent, future pavements should also be multifunctional, i.e. fulfill other purposes than just serving as platforms for traffic. For example, porous asphalt pavements could additionally serve as intermediate flood relieve and water retention, or as part of a pavement sandwich construction for mitigating urban heat island effects. Different concepts are under discussion, based either on moisture evaporation, by filling porous pavements with slowly moisture releasing "spongy" grout (like presented 2017 by PWRI in Tsukuba, Japan, http://www.dohkenkyo.com/english/ tc_water.html) or on liquid water circulation within porous pavement layers as part of road sandwich structures [1]. Similar pavements could also serve for solar energy harvesting, thus replacing more traditional systems with pipes. One possibility in that context would be to create a meandering pipe-like system that is directly imprinted in a mastic asphalt layer, filling the imprinted "pipes" with a stony

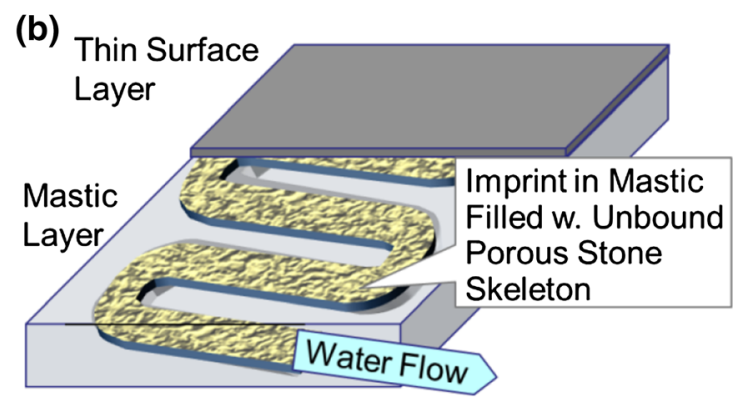

Fig. 6 Schemas: a horizontal extruder compactor, b imprinted pipes for water flow 
unbound skeleton of high continuous pore volume for water flow and cover this system with a thin dense, probably reinforced, surface layer (Fig. 6b). However, with the available road material components of today, all these porous road systems are challenged by the fact that they are expected to fulfill their function under intensive continuous water flow and, therefore, under high risk of suffering water damage. Nevertheless, new kind of pavement materials may change this situation.

All future pavement developments mentioned in this section will require new types of materials and road structures, resulting in new construction and design methods based on improved engineering and environmental understanding of the materials and systems. For Rilem this means an exciting development, triggering plenty of challenging and inspiring interdisciplinary questions. These questions will certainly serve as exciting starting points for future TCs, aiming at comparative research and international collaboration for establishing and evaluating scientifically sound and practicable recommendations eventually leading to well-founded standards for reliable performance testing.

\section{Conclusions}

During the last 50 years, Rilem has proven to be a strong and successful player in continuously complementing the experimental and theoretical tools for meaningful evaluation of the key influence parameters in relation to the composition of bituminous materials and for improved understanding of their chemophysical and mechanical functioning from nano- to mega-scale, in particular with respect to road pavement applications. Its international network together with its general principle of performing research work on a fully voluntary basis has created a wealth of results that resulted in recommendations with prestandardization character, in-depth state of the art reports, highly acknowledged scientific publications of its TC members and well attended conferences with elaborate proceedings of long lasting value not only for practitioners but also for students and young professionals. The emerging new developments of bituminous materials and systems in combination with new materials will certainly be a challenge for Rilem, due to their complexity and due to the risk that voluntary work is not necessarily providing an immediate return of investment, e.g. in case of TC members, who report to an industrial employer. Alliances of Rilem with project funding organizations without betraying Rilem's mission and independence may be a way to overcome or mitigate this situation. Nevertheless, the long term success of Rilem shows that its principles and concepts were sustainable, so far, and may also be beneficial for the whole bituminous materials community in the future.

\section{Compliance with ethical standards}

Conflict of interest The author declares that he has no conflict of interest.

Open Access This article is distributed under the terms of the Creative Commons Attribution 4.0 International License (http:// creativecommons.org/licenses/by/4.0/), which permits use, duplication, adaptation, distribution and reproduction in any medium or format, as long as you give appropriate credit to the original author(s) and the source, provide a link to the Creative Commons license and indicate if changes were made.

\section{References}

1. Asfour S, Bernardin F, Toussaint E (2018) Experimental validation of $2 \mathrm{D}$ hydrothermal modelling of porous pavement for heating and solar energy retrieving applications. RMPD. https://doi.org/10.1080/14680629.2018.1525418

2. Jeoffroy E, Bouville F, Bueno M, Studart A, Partl MN (2018) Iron-based particles for the magnetically-triggered crack healing of bituminous materials. Constr Build Mater 164:775-782. https://doi.org/10.1016/j.conbuildmat.2017.12.223

3. Lee HJ, Kim YR (1998) Viscoelastic continuum damage model of asphalt concrete with healing. J Eng Mech 124(11):1224-1232

4. Naus R, Bhairo P, Voskuilen J, van Montfort J (2010) Rollpave: a prefabricated asphalt wearing course. http:// data.abacus.hr/h-a-d/radovi_s_kongresa/nagoya_japan_ 2010/90193.pdf. Accessed July 2018

5. Olard F, Di Benedetto H (2003) General “2S2P1D” model and relation between the linear viscoelastic behaviors of bituminous binders and mixes. RMPD 4(2):185-224. https://doi.org/10.1080/14680629.2003.9689946

6. Partl M, Rösli A (1984) Näherungsverfahren zur Berechnung der Verformungen von Asphalt unter wechselnder Zug/Druck-Kriechbeanspruchung. Bitumen 1:8-13 (in German)

7. Partl M, Rösli A (1985) An approximation of uniaxial creep during alternating tension-compression step loading at constant temperature. Int J Solids Struct 21(3):235-244

8. Refaa Z, Kakar MR, Stamatiou A, Worlitschek J, Partl MN, Bueno M (2018) Numerical study on the effect of phase change materials on heat transfer in asphalt concrete. Int $\mathbf{J}$ Therm Sci 133:140-150. https://doi.org/10.1016/j. ijthermalsci.2018.07.014 
9. Schapery RA (1997) Nonlinear viscoelastic and viscoplastic constitutive equations based on thermodynamics. Mech Time Depend Mater 1(2):209-240

10. Xiao J, Zou X, Xu W (2017) A self-powered wireless sensor for smart and autonomous pavement. Sensors 17(10):2207. https://doi.org/10.3390/s17102207

\section{Rilem recommendations}

11. BM-1: Terminology of hydrocarbon binders by TC17-BM, TC56-MHM, TC 101-BAT. RILEM technical recommendations for the testing and use of construction materials, pp 273-274. Taylor \& Francis, CRC Press, ISBN: 978-0419188100 (1994); Mater Struct 22:237-239 (1989)

12. BM-2: Methods of sampling hydrocarbon binders by TC17BM, TC56-MHM. RILEM technical recommendations for the testing and use of construction materials, pp 275-284. Taylor \& Francis, CRC Press. ISBN: 978-0419188100 (1994); Mater Struct 15(86) (1982)

13. BM-3: Determination of density or relative density of hydrocarbon binders-capillary stoppered pyknometer method by TC17-BM, TC56-MHM. RILEM technical recommendations for the testing and use of construction materials, pp 285-289, Taylor \& Francis, CRC Press, ISBN: 978-0419188100 (1994); Mater Struct 15(90) (1982)

14. BM-4: Determination of needle penetration of hydrocarbon binders by TC17-BM, TC56-MHM. RILEM technical recommendations for the testing and use of construction materials, pp 290-294. Taylor \& Francis, CRC Press, ISBN: 978-0419188100 (1994); Mater Struct 16(93) (1984)

15. BM-5: Recovery method with rotary evaporator of the soluble binder from bituminous mixes by TC56-MHM. Mater Struct 21:151-160 (1988); RILEM technical recommendations for the testing and use of construction materials, pp 295-296, Taylor \& Francis, CRC Press, ISBN: 978-0419188100 (1994)

16. English-French-German dictionary of technical terms related to hydrocarbon binders, hydrocarbon composite material, processes for removing pavement material and for rehabilitation of asphalt pavements by TC 101-BAT (revised). Mater Struct 25:171-185 (1992)

17. Di Benedetto H, Partl MN, Francken L (2001) De La Roche Saint André C (2001) Stiffness testing for bituminous mixtures by TC 182-PEB. Mater Struct 34:66-70

18. Di Benedetto H, Del La Roche C, Baaj H, Pronk A, Lundström R (2004) Fatigue of bituminous mixtures by TC 182-PEB; RILEM TC 182-PEB. Mater Struct 37:202-216

19. Sybliski D, Vanelstraete A, Partl MN (2004) Recommendation of RILEM TC 182-PEB on bending beam and rheometer measurements of bituminous binders by TC 182-PEB. Mater Struct 37:539-546

20. Perraton D, Di Benedetto H, Sauzéat C, De La Roche C, Bankowski W, Partl MN, Grenfell J (2010) Rutting of bituminous mixtures: wheel tracking tests campaign analysis by TC 206-ATB. Mater Struct 37:1031-1046

21. Gabet T, Di Benedetto H, Perraton D, De Vischer J, Gallet T, Bankowski W, Olard F, Grenfell J, Bodin D, Sauzéat C (2011) French wheel tracking Round Robin test on a polymer modified bitumen mixture by TC 206-ATB. Mater Struct 37:1031-1046
22. Graziani AA, Di Benedetto H, Perraton D, Sauzéat C, Hofko B, Poulikakos LD, Pouget S (2017) Recommendation of RILEM TC 237-SIB on complex Poisson's ratio characterization of bituminous mixtures by TC 237-SIB. Mater Struct 50:142

23. Petit C, Chabot A, Destrée A, Raab C (2018) Recommendation of RILEM TC 241-MCD on interface debonding behavior in pavements by TC 241-MCD. Mater Struct 51:96. https://doi.org/10.1617/s11527-018-1223-y

24. Cannone Falchetto A, Tebaldi G, Dave E, Hugener M, Perraton D, Grilli A, Pasetto M, Lo Presti D, Loizos A, Jenkins K, Apeagyei A, Grenfell J, Bocci M (2018) Recommendation of RILEM TC237-SIB on cohesion test of recycled asphalt by TC 237-SIB. Mater Struct 51:117. https://doi.org/10.1617/s11527-018-1238-4

25. Porot L, Soenen H, Apeagyei A, Grenfell J, Vansteenkiste S, Chailleux E (in press) Recommendation of RILEM TC 237-SIB on affinity between aggregates and bituminous binder testing by TC 237-SIB, TC approved. Mater Struct

26. Cannone Falchetto A, Tebaldi G, Dave E, Hugener M, Perraton D, Grilli A, Pasetto M, Lo Presti D, Loizos A, Jenkins K, Apeagyei A, Grenfell J, Bocci M (in press) Recommendation of RILEM TC237-SIB: protocol for characterization of recycled asphalt (RA) materials for pavement applications by TC 237-SIB. https://doi.org/10. 1617/s11527-018-1253-5

27. Cannone Falchetto A, Tebaldi G, Dave E, Hugener M, Perraton D, Grilli A, Lo Presti D, Pasetto M, Loizos A, Jenkins K, Apeagyei A, Grenfell J, Bocci M (ready for submission) Recommendation of RILEM TC237-SIB on Fragmentation Test for Recycled Asphalt by TC 237-SIB, TC approved. Mater Struct

\section{Rilem state-of-the-art reports}

28. Vanelstraete A, Francken L (eds) (1997) Prevention of reflective cracking in pavements. Rilem report 18, Thompson Professional, E \& FN Spon. ISBN: 0-203-627237

29. Francken L (ed) (1998) Bituminous binders and mixes. Rilem report 17, E \& FN Spon. ISBN: 978-041922870

30. Partl MN, Piber H (eds) (2001) Pavement performance prediction and evaluation (PPPE) interlaboratory tests, part I, II III. Rilem report 29. Electronic, e-ISBN: 2-912143-683. https://doi.org/10.1617/2912143683.001

31. Partl MN, Bahia HU, Canestrari F, De La Roche C, Di Benedetto H, Piber H, Sybilski D (eds) (2013) Advances in interlaboratory testing and evaluation of bituminous material. Rilem state-of-the-art report, vol 9, Springer. ISBN: 978-94-007-5103-3

32. Partl MN, Porot L, Di Benedetto H, Canestrari F, Marsac P, Tebaldi G (eds) (2018) Testing and characterization of sustainable bituminous materials and systems. Rilem state-ofthe-art report, vol 24, Springer. ISBN: 978-3-319-71022-8

33. Buttlar WG, Chabot A, Dave EV, Petit C, Tebaldi G (eds) (2018) Mechanisms of cracking and debonding in asphalt and composite pavements. Rilem state-of-the-art report, vol 28, Springer. ISBN: 978-3-319-76848-9 


\section{Rilem proceedings}

34. Hütter A (ed) (1969) Bitumen im Bauwesen. Rilem Conference in Dresden. Separatdruck der Wissenschaftlichen Zeitschrift der TU Dresden 18 H 3., Reihe 7, Nr 2

35. Zakar P, Huet J (eds) (1975) Test on bitumen and bituminous materials. In: Proceedings vol 1 and vol 2 of Rilem symposium in Budapest, OMKDK Technoinform, Budapest. ISBN: 963-592-004-0, 963-592-033-4

36. Zakar P, Huet J (eds) (1979) Temperature susceptibility of the consistency of hydrocarbon binders. In: Proceedings of Rilem symposium in Darmstadt, OMKDK Technoinform, Budapest. ISBN: 963-592-154-3

37. Ajour A-M, Huet J (eds) (1983) Testing of hydrocarbons binders and materials. In: Proceedings of RILEM 3rd symposium in Belgrade, vol 1-2, Yugoslav Association for Testing and Research of Materials and Structures

38. Fritz HW, Huschek S, Pigois ML (eds) (1983) Essais mécaniques pratiques de formulation et de contrôle des enrobés Bitumineux. In: Proceedings RILEM colloque in Belgrade, Print RILEM TC 56-MHM

39. Verstraeten J (ed) (1986) Mix design and quality control for bituminous mixes. In: Proceedings RILEM seminary in Olivet, Print RILEM TC 56-MHM

40. Svetel D, Fritz HW (eds) (1988) Formulation, control and behaviour of polymer modified bitumens either for waterproofing or for road construction. In: Proceedings of RILEM seminar in Dubrovnik. The Highway Institute, Kumodraska 257, Belgrade (1989)

41. Rigo JM, Degeimbre R (eds) (1989) Reflective cracking in pavements: assessment and control. In: Proceedings of Rilem conference in Liège, State University of Liège

42. Fritz HW, Eustaccio E (eds) (1990) Mechanical tests for bituminous mixes, characterization, design and quality control. In: 4th International Rilem symposium in Budapest. RILEM proceedings 8, vol 1. Chapman and Hall, London. ISBN: 9789638192387

43. Rigo JM, Degeimbre R, Francken L (eds) (1993) Reflective cracking in pavements: state of the art and design recommendations. In: 2nd International Rilem conference in Liège, proceedings 20, Taylor \& Francis. ISBN: 0419-18220-9

44. Francken L, Beuving E, Molenaar AAA (eds) (1996) Reflective cracking in pavements: design and performance of overlay systems. In: 3rd International Rilem conference Maastricht. Rilem proceedings 33, Chapman \& Hall, E \& FN Spon. ISBN: $041922260 \mathrm{X}$

45. Di Benedetto H, Francken L (eds) (1997) Mechanical tests for bituminous materials: recent improvements and future prospects, MTBM97. In: 5th Internatational RILEM symposium in Lyon. Proceedings MTBM97, Balkema. ISBN: 90-5410-876-2

46. Abd El Halim AO, Taylor DA, Mohamed El HH (eds) (2000) Reflective cracking in pavements: research and practice. In: 4th International Rilem conference in Ottawa. Rilem proceedings PRO 11, Rilem publications S.A.R.L. ISBN: 2-912143-14-4

47. Partl MN (ed) (2003) Performance testing and evaluation of bituminous materials. In: 6th International RILEM symposium in Zürich, PTEBM03, Rilem Publications S.A.R.L. ISBN 2-912143-45-7

48. Petit C, Al-Qadi IL, Millien A (eds) (2004) Cracking in pavements: mitigation, risk assessment and prevention. In: 5th International Rilem conference in Limoges, proceedings PRO37, Rilem Publications S.A.R.L. ISBN: 2-912143-47-0

49. Al-Qadi IL, Scarpas T, Loizos A (eds) (2008) Pavement cracking: mechanisms, modeling, detection, testing, and case histories. In: 6th International Rilem conference in Chicago, Taylor \& Fancis, CRC Press. ISBN: 978-0-41547575-4

50. Loizos A, Partl MN, Scarpas T, Al-Qadi IL (eds) (2009) Advanced testing and characterization of bituminous materials. In: 7th International Rilem symposium in Rhodos, vol 1-2, Taylor \& Fancis, CRC Press. ISBN: 978-0415-55854-9

51. Scarpas A, Kringos N, Al-Qadi I, Loizos A (eds) (2012) 7th Rilem international conference on cracking in pavements: mechanisms modeling testing detection prevention and case histories in Delft, vol 1-2. Rilem bookseries, vol 4, Springer. ISBN: 978-94-007-4565-0

52. Kringos N, Birgisson B, Frost D, Wang L (eds) (2013) Multi-scale modeling and characterization of infrastructure materials. In: International Rilem symposium in Stockholm, vol 8. Rilem bookseries, Springer. ISBN: 978-94-07-6877-2

53. Canestrari F, Partl MN (eds) (2015) 8th RILEM international symposium on testing and characterization of sustainable and innovative bituminous materials in Ancona, vol 11. Rilem bookseries (2016), Springer. ISBN: 978-94-0177341-6

54. Chabot A, Buttlar WG, Dave VEV, Petit C, Tebaldi G (eds) (2016) 8th RILEM international conference on mechanisms of cracking and debonding in pavements in Nantes, vol 13. Rilem bookseries, Springer. ISBN: 978-94-024-0866-9

55. Poulikakos LD, Cannone Falchetto A, Wistuba MP, Hofko B, Porot P, Di Benedetto H (eds) (2018) Rilem 252-CMB symposium on chemo-mechanical characterization of bituminous materials in Braunschweig, vol 20. Rilem bookseries (2019), Springer. ISBN: 978-3-030-00475-0 